\title{
Price Effects of Multimarket Contact Among Movie Chains in Small U.S. Metropolitan Areas
}

\author{
Robert M. Feinberg \\ American University
}

August 2013

\begin{abstract}
Movie theater chains are ubiquitous in major metropolitan areas of the U.S., with generally two or more of these large chains present. However in smaller metropolitan areas, we see far more variation in the role of these chains. This allows for an opportunity to see whether multimarket contact (MMC) among these firms has an impact on movie pricing in these smaller markets. In this paper, data on movie pricing, market structure, and income and population characteristics are obtained for 79 small metropolitan areas - those with under 250,000 people - which are not part of larger "consolidated" metropolitan areas. A crude measure of MMC is found to indeed be related to price increases in the smallest of these markets.
\end{abstract}




\section{Price Effects of Multimarket Contact Among Movie Chains in Small U.S. Metropolitan Areas}

\section{Introduction}

There has been much interest in recent years in empirical investigations of the role of multimarket contact among firms in determining the nature of competitive performance in markets. In addition to early cross-market studies (Scott 1982, Feinberg 1985), evidence of “mutual forbearance” effects via MMC has been found in banking, cement, telecommunications and airlines. ${ }^{1}$ We investigate the issue here for another industry, not previously studied in this regard.

Movie theater chains are ubiquitous in major metropolitan areas of the U.S., with generally two or more of these large chains present. However in smaller metropolitan areas, we see far more variation in the role of these chains. This allows for an opportunity to see whether MMC among these firms has an impact on movie pricing in these smaller markets. In this paper, data on movie pricing, market structure, and income and population characteristics are obtained for 79 small metropolitan areas - those with under 250,000 people - which are not part of larger “consolidated” metropolitan areas.

\footnotetext{
${ }^{1}$ See Heggestad and Rhoades (1978), Evans and Kessides (1994), Jans and Rosenbaum (1997), Parker and Röller (1997), and Ciliberto and Williams (2010).
} 


\section{Conceptual framework}

Whether derived from conjectural variations models of oligopoly behavior (Feinberg 1984) or game theoretic approaches (Bernheim and Whinston 1990), the essence of the potential threat posed by MMC to competitive performance is that firms will anticipate that aggressive actions in one market will bring a competitive response not simply in that market but in other markets in which they meet. ${ }^{2}$ In terms introduced in Feinberg (1985), they will see those "othermarket” sales as “sales-at-risk”. This may lead to a greater likelihood of tacit collusion.

The key, though, is that those "sales-at-risk" are large relative to the gains from competitive actions in the market in question (or - what is the same thing - the market in question is relatively small, or unimportant in the firm's profit calculus). The other consideration is that since MMC can be considered merely a "facilitating device" in promoting tacit collusion, it is not likely to be able to overcome the competition emerging in large markets with large numbers of firms. What seems the most promising scenario is relatively small markets where MMC may be able to cement relationships in avoiding competitive behavior. What follows in an effort to explore this insight in the movie theater business.

\section{Data construction}

The major movie theater chains - Regal, AMC, Cinemark, Carmike - and some of the smaller chains as well have a presence in virtually all large metropolitan areas, suggesting that MMC applies to all. Where there is more variation is in smaller markets. However, in the very smallest (now called “micropolitan areas” by the Census Bureau), we typically find just a single movie theater (or none) and hence no opportunity for MMC to play a role. The sample analyzed in this paper is that of metropolitan areas of under 250,000 population (as of 2012 estimates)

\footnotetext{
${ }^{2}$ Edwards (1955) is usually thought of as the originator of this idea.
} 
which are not part of larger “consolidated” metropolitan statistical areas - there are 79 such markets in the U.S. ranging from Lewiston, Idaho (population 61,419) to Binghamton, New York (population 248,538), with the mean population in the sample 149,312 (approximately equal to the population of the Texarkana, Texas metropolitan area).

For each of these markets, I have identified the theaters present (during the last week of July 2013), whether any of them are chains, their populations (for 2012) and per-capita personal income (for 2011), and a representative non-discounted weekend evening (non-3D) movie price (for Friday evening August 2, 2013). While traditional government sources (Census and BEA) were used for population and income estimates, the primary source of data on numbers and types of movie theaters and ticket prices was the website Fandango.com, supplemented by web searches for situations where Fandango did not report ticket prices and to verify a theatre’s association with a chain (usually for smaller chains). As the focus is on independent sources of competition within markets, multiple theatres owned by the same chain or local group were coded as a single theater. In addition, an arbitrary decision was made that a single-screen theater (usually, but not always, an "art house”, showing smaller independent movies) was not a serious competitor in the market, while those with 2 or more screens would be included.

While, ideally, market structure would be measured by a Herfindahl index or some other indicator of concentration, market share data are not available; this is proxied simply by the number of independent sources of competition (either a chain or local firm) in the market. Similarly MMC is treated as a 0/1 variable, with a value of one corresponding to a market where some firms present meet in another metropolitan area. 
Table 1 presents descriptive statistics. Notice that there is substantial variation across the 79 markets in terms of population (POP) and per-capita income (INCOME). While there is a reasonable range of ticket prices, these cluster quite a bit around the mean of $\$ 9.40$. The number of competing firms (NUMBER) ranges from 1 to 5, and 22.7\% of the markets have firms who meet elsewhere (MMC). Given the relatively small size of these markets it is likely that the "other" markets in which these firms meet is larger (and this is certainly true for the smallest of these markets), raising the concerns that movie theaters in these markets may have that the small gains they may experience from deviating from tacit collusion here will cost them more in their larger/more-important market interactions.

\section{Results}

The econometric approach is quite simple, using OLS with robust standard errors. The movie ticket price is estimated as a function of market size, per-capita income (intended as a proxy for local cost-of-living), the number of competing firms in the market, and the indicator variable for MMC. All continuous variables - PRICE, POP, and INCOME - are expressed in natural logs; this implies that the effect of the dummy variable MMC can be seen as a percentage change in price due to the possibility of mutual forbearance behavior. ${ }^{3}$

Table 2 presents the results. In column (1) we see that higher-income markets have higher movie ticket prices (as anticipated, viewing per-capita income either as a demand side or cost-side proxy), with weak support for larger markets having higher prices. No significant impact is seen of MMC or NUMBER. As noted earlier, the intuition of the mutual forbearance

\footnotetext{
${ }^{3}$ The results with all variables in levels are quite similar.
} 
hypothesis resulting from MMC is that this is more likely to follow as other markets -- and the sales "at-risk" in those -- are more important. Operationalizing that, we introduce an interaction term between MMC and POP, with results in column (2); we now find, as expected, both MMC and the interaction term to be statistically significant (at 5\%) suggesting a large positive impact of MMC on PRICE in the smallest markets, with the effect diminishing as markets increase in size.

At the mean market size the estimated impact of MMC is to raise ticket prices by $4.76 \%$, but the implications for extremes of population are quite different: at 61,419 (the smallest market in the sample) the predicted effect is to raise PRICE by over 23\%, while at 248,538 (the largest market in the sample) MMC actually lowers price by 5.75\%. Markets under 188,076 in population (77\% of the sample) are predicted to experience a rise in price due to MMC.

\section{Conclusion}

The results presented here are certainly not definitive, yet they add to the growing body of evidence suggesting that MMC among firms can play a role in facilitating tacit collusion. At the same time though, they do provide some caution in viewing the importance of the mutual forbearance hypothesis. We are most likely to see these effects in moderately concentrated markets which are small enough that gains from competitive moves are outweighed by possible retaliatory actions addressed elsewhere. Yet there are markets that meet these conditions and one should keep MMC in mind in evaluating the potential for market power to be exercised. 


\section{References}

Bernheim, B. Douglas and Michael D. Whinston, "Multimarket Contact and Collusive Behavior,” Rand Journal of Economics, Vol. 21, 1990, pp. 1-26.

Ciliberto, Federico and Jonathan W. Williams, “Does Multimarket Contact Facilitate Tacit Collusion? Inference on Conduct Parameters in the Airline Industry,” Working Paper, December 2010.

Edwards, Corwin D., “Conglomerate Bigness as a Source of Power," in Business Concentration and Price Policy (NBER Conference Report) (Princeton, NJ: Princeton University Press, 1955), pp. 331-352.

Evans, William N. and Ioannis N. Kessides, "Living by the "Golden Rule": Multimarket Contact in the U. S. Airline Industry,” Quarterly Journal of Economics , Vol. 109, No. 2, 1994, pp. 341366.

Feinberg, Robert M., "Mutual Forbearance as an Extension of Oligopoly Theory,” Journal of Economics and Business, Vol. 36, May 1984, pp. 242-249.

Feinberg, Robert M., “'Sales-at-Risk': A Test of the Mutual Forbearance Theory of Conglomerate Behavior,” Journal of Business, Vol. 58, No. 2, 1985, pp. 225-241.

Heggestad, Arnold and Stephen A. Rhoades, "Mulit-market Interdependence and Local Market Competition in Banking,” Review of Economics and Statistics, Vol. 60, May 1978, pp. 523-532.

Jans, Ivette and David I. Rosenbaum, "Multimarket Contact and Pricing: Evidence from the U.S. Cement Industry,” International Journal of Industrial Organization, Vol. 15, No. 3, May 1997, pp. 391-412.

Parker, Philip M. and Lars-Hendrik Röller, "Collusive Conduct in Duopolies: Multimarket Contact and Cross-Ownership in the Mobile Telephone Industry,” RAND Journal of Economics, Vol. 28, No. 2, Summer 1997, pp. 304-322.

Scott, John T., "Multimarket Contact and Economic Performance,” Review of Economics and Statistics, Vol. 64, August 1982, pp. 368-375. 
Table 1. Descriptive Statistics $(n=79)$

Mean S.D. Min Max

$\begin{array}{lcccc}\text { PRICE (\$) } & 9.44 & 0.93 & 6 & 11.50 \\ \text { POP (000) } & 149.3 & 48.6 & 61.4 & 248.5 \\ \text { INCOME (\$000) } & 35.8 & 5.1 & 27.1 & 54.1 \\ \text { NUMBER } & 1.59 & 0.78 & 1 & 5 \\ \text { MMC } & 0.23 & 0.42 & 0 & 1\end{array}$


Table 2. Regression Results, Dependent Variable $=\operatorname{lnPRICE}(\mathrm{n}=79)$

Estimated Coefficients

$$
\text { (1) }
$$

$\ln \mathrm{POP}$

$\operatorname{lnINCOME}$

NUMBER

MMC

$\mathrm{MMC} * \ln \mathrm{POP}$
$0.068^{*}$

$(0.040)$

$0.182^{* *}$

(0.075)

$-0.019$

$(0.015)$

0.021

$(0.035)$

$---$
(2)

$0.098 * *$

(0.044)

$0.206 * * *$

$(0.076)$

$-0.016$

$(0.016)$

$2.506^{* *}$

(1.021)

$-0.207 * *$

(0.086)

Robust standard errors in parentheses below estimated coefficients.

*** Significance at $1 \%$

** Significance at $5 \%$

* Significance at $10 \%$ 